Article

\title{
Work-Related Psychological Wellbeing: Testing the Balanced Affect Model among Anglican Clergy
}

\author{
Leslie Francis ${ }^{1, *}$, Patrick Laycock ${ }^{2}$ and Christine Brewster ${ }^{3}$ \\ 1 Warwick Religions and Education Research Unit, Centre for Education Studies, The University of Warwick, \\ Coventry CV4 7AL, UK; leslie.francis@warwick.ac.uk \\ 2 Emeritus Professor, School of Mathematics, Alan Turing Building, University of Manchester, Oxford Road, \\ Manchester M13 9PL, UK; pjlaycock@manchester.ac.uk \\ 3 Independent scholar, Wrexham Glyndŵr University, Mold Road, Wrexham LL11 2AW, UK; \\ cbmichaelmas@gmail.com \\ * Correspondence: leslie.francis@warwick.ac.uk; Tel.: +44-0-24-7652-2539
}

Received: 12 May 2017; Accepted: 12 June 2017; Published: 28 June 2017

\begin{abstract}
Poor work-related psychological health and professional burnout remain issues of concern among clergy across denominations and across cultures. Maslach's three-component model of burnout remains the most frequently employed conceptualization and measure in clergy research. Maslach proposes a sequential model of burnout. An alternative approach has been offered by the Francis Burnout Inventory that comprises two components. Francis proposes a balanced affect model of burnout according to which negative affect (emotional exhaustion) is offset by positive affect (satisfaction in ministry). This study draws on data provided by around 658 clergy serving in the Church of England to test this balanced affect model. Employing independent measures of burnout, the data demonstrated the significance of the interaction term between positive affect and negative affect in predicting individual differences in burnout. In other words, as positive affect increases the effects of negative affect decrease.
\end{abstract}

Keywords: clergy; burnout; wellbeing

\section{Introduction}

Poor work-related psychological health—as reflected in professional burnout—is a matter of theoretical and practical concern across the caring professions, among which the clerical profession is no exception. Precisely how burnout is conceptualized and assessed has implications not just for the identification and diagnosis of individuals at risk of burnout and consequently posing risks to themselves and to their clients, but also for the nature of targeted intervention and strategic prevention.

The best known and best established conceptualization and operationalization of professional burnout is the model proposed by Maslach and assessed by various forms of the Maslach Burnout Inventory (Maslach and Jackson 1986). This model conceptualizes and assesses professional burnout as comprising three components: styled emotional exhaustion, depersonalization, and lack of personal accomplishment. According to the Maslach model, these three components are linked in a sequential model: professional burnout begins with emotional exhaustion; emotional exhaustion leads to depersonalization; and depersonalization leads to lack of personal accomplishment. While this model is conceptually coherent, there is a lack of longitudinal evidence against which it has been tested. It is also far from clear how this conceptual model of burnout generates insight into strategies for targeted intervention and methods of prevention.

In the Maslach Burnout Inventory, emotional exhaustion is assessed by a nine-item subscale. The items describe feelings of being emotionally overextended and exhausted by one's work. The item with the highest factor loading on this dimension is one referring directly to burnout, "I feel burned out 
from my work." Depersonalization is assessed by a five-item subscale. The items describe an unfeeling and impersonal response toward the individuals in one's care. An example item on this dimension is "I feel I treat some recipients as if they were impersonal objects." Personal accomplishment is assessed by an eight-item subscale. The items describe feelings of competence and successful achievement in one's work with people. An example item on this dimension is "I feel I'm positively influencing other people's lives through my work."

The Maslach Burnout Inventory has been employed in a series of studies among clergy, including work reported by Warner and Carter (1984), Strümpfer and Bands (1996), Rodgerson and Piedmont (1998), Stanton-Rich and Iso-Ahola (1998), Virginia (1998), Evers and Tomic (2003), Golden et al. (2004), Raj and Dean (2005), Miner (2007a; 2007b) and Doolittle (2007; 2010), Chandler (2009), Joseph et al. (2010), Buys and Rothmann (2010), Parker and Martin (2011), Rossetti （2011), Küçüksüleymanoğlu (2013), Herrera et al. (2014), Crea and Francis (2015), and Adams et al. (2017). Although the Maslach Burnout Inventory has been used in studies among clergy, some reservations have been expressed that the items are not particularly well-worded to capture the experience and working practices of religious professionals. For example, it has been noted that some clergy seem uncomfortable referring to those among whom they minister as "clients". In response to this criticism, Rutledge and Francis (2004) obtained permission from the Consulting Psychologist Press to reshape some of the items of the Maslach Burnout Inventory to better reflect the experience and language of the clerical profession, and at the same time to develop some new items relevant to the clerical profession that would bring the three subscales to the same length of ten items each. A series of studies has reported findings employing this modified form of the Maslach Burnout Inventory in the United Kingdom among Roman Catholic priests engaged in parochial ministry (Francis et al. $(2004 ; 2007)$ ) and among Anglican parochial clergy (Francis and Rutledge 2000; Francis and Turton (2004a; 2004b); Randall (2004; 2007); Rutledge 2006; Turton and Francis 2007). The modified Maslach Burnout Inventory for use among clergy has been further modified and refined by Hills et al. (2004).

A more recent conceptualization and operationalization of burnout is proposed by Francis and assessed by the Francis Burnout Inventory (Francis et al. 2005). Unlike the Maslach Burnout Inventory, the Francis Burnout Inventory was developed in the first instance for use among clergy and has been subsequently adapted for use among other professional groups. This model conceptualizes and assesses professional burnout as comprising two components: styled emotional exhaustion in ministry and satisfaction in ministry. According to Francis, these two components are linked not sequentially but by means of the classic model of balanced affect as described by Bradburn (1969). According to the balanced affect model, positive affect (satisfaction in ministry) and negative affect (emotional exhaustion in ministry) are not opposite ends of a single continuum, but two separate continua. According to this model, it is totally reasonable for individual clergy to experience simultaneously high levels of positive affect and high levels of negative affect. According to this model of balanced affect, warning signs of poor work-related psychological health occur when high levels of negative affect coincide with low levels of positive affect.

In the Francis Burnout Inventory negative affect is assessed by the 11-item Scale of Emotional Exhaustion in Ministry. Items with high factor loadings on this dimension include: "Fatigue and irritation are part of my daily experience", "I feel drained by fulfilling my ministry role", and "I am feeling negative and cynical about the people with whom I work". Positive affect is assessed by the 11-item Scale of Satisfaction in Ministry. Items with high factor loadings on this dimension include: "The ministry here gives real purpose and meaning to my life", "I feel very positive about my ministry here", and "I am really glad that I entered ministry".

The Francis Burnout Inventory is now being employed in a growing number of studies among clergy, including work reported by Francis et al. (2008; 2009; 2012; 2013a; 2013b; 2013; 2015), Robbins and Francis (2010; 2014), Brewster et al. (2011), Robbins et al. (2012), 
Barnard and Curry (2012), Randall (2013a; 2013b), Sterland (2015), Francis and Crea (2015), and Durkee-Lloyd (2016).

If the balanced affect model of professional burnout proposed by the Francis Burnout Inventory is a current reflection of the nature of burnout among clergy, this model generates some clear insights into strategies for targeted interventions and methods of prevention. If satisfaction in ministry ameliorates the effects of emotional exhaustion in ministry, even when the causes of exhaustion may not be easily and quickly removed, the nurturing of new forms of satisfaction in ministry may to some extent serve to ameliorate the effects of emotional exhaustion on personal wellbeing and work performance. There are clear practical benefits as well as scientific benefits in checking the adequacy of the balanced affect model.

In a pioneering study conducted among clergy serving in the Presbyterian Church (USA), Francis et al. (2011) set out to test the balanced affect model of the Francis Burnout Inventory employing the two 11-item scales concerned with emotional exhaustion in ministry and satisfaction in ministry. This study employed two independent measures of burnout. Self-perceived physical health was assessed by the question: "How would you rate your overall health at the present time?" with the following four response options: excellent, good, fair, and poor. Self-perceived burnout was assessed by the question: "To what extent do you think you are suffering from burnout in your current call?" with the following four response options: to a great extent, to some extent, to a small extent, and not at all. The research method examined the incremental impact on these two independent measures of burnout of the interaction term created by the product of the two measures of positive affect and negative affect after taking into account the impact of these two measures considered separately. Consistent with the theory of balanced affect, the data demonstrated that the mitigating effects of positive affect on professional burnout increased with increasing levels of negative affect.

While the study reported by Francis et al. (2011) clearly provides support for the balanced affect model of professional burnout as operationalized by the two scales of the Francis Burnout Inventory, the generalizability of these findings may be limited by two considerations: the specific group of clergy (Presbyterian clergy in the USA) among whom the data were collected and the specific focus of the two independent measures of burnout employed.

\section{Research Question}

Against this background, the aim of the present study is to extend the work of Francis et al. (2011) by testing this theory among a very different group of clergy (Anglican clergy in England), and using three different independent measures of burnout: thoughts of leaving ministry, psychological distress, and psychosomatic ailments.

This primary aim leads to the specification of the following three research questions. The first two of these research questions are necessary to prepare the ground for addressing the third research question:

- to identify the levels of burnout reflected in the three independent measures of thoughts of leaving ministry, psychological distress, and psychosomatic ailments;

- to examine the psychometric properties of the two measures of positive affect and negative affect proposed by the Francis Burnout Inventory;

- to test the balanced affect model through examination of the effect of the interaction term between emotional exhaustion and satisfaction in ministry in predicting individual differences in reported levels of psychological distress, psychosomatic ailments, and thoughts of leaving ministry.

\section{Methods}

\subsection{Procedure}

A detailed questionnaire was sent to a random sample of Anglican clergy serving in rural multi-church benefices in England. The names and addresses of Anglican clergy are in the public 
domain. A response rate of $47 \%$ generated 722 completed questionnaires. The present analyses are based on those respondents serving in full-time paid posts, part-time paid posts, full-time self-supporting posts, and part-time self-supporting posts involving multiple churches and who had completed the majority of key measures listed below $(N=658)$.

\subsection{Sample}

The 658 participants on whom the analyses are based comprised 494 clergymen and 164 clergywomen; 28 were in their thirties, 143 were in their forties, 278 were in their fifties, 201 were in their sixties, and 8 were in their seventies. In terms of marital status, the majority were married (520), 50 were single, 22 were widowed, 21 were divorced, 5 were widowed and re-married, 31 were divorced and re-married, 4 were separated, 1 was cohabiting with a same sex partner, and 4 failed to disclose this information. In terms of pastoral responsibilities, 22 were responsible for fewer than 3 churches, 216 for 3 churches, 178 for 4 churches, 92 for 5 churches, 131 for at least 6 churches, and 12 failed to disclose this information.

\subsection{Measures}

Work-related psychological health was assessed by the two scales reported by Francis et al. (2005): the Scale of Emotional Exhaustion in Ministry (SEEM) and the Satisfaction in Ministry Scale (SIMS). Each scale comprised 11 items assessed on a five-point scale: agree strongly (5); agree (4); not certain (3); disagree (2), and disagree strongly (1). Example items from SEEM include: "I feel drained in fulfilling my functions here", and "I am less patient with people here than I used to be". Example items from SIMS include: "I feel very positive about my ministry here", and "I am really glad that I entered the ministry". The 11 items from the SEEM and the 11 items from the SIMS were presented alternately. Scale properties have been reported elsewhere in a study of over 6000 clergy drawn from a range of denominations in Australia, New Zealand, and England (Francis et al. 2005), in which both scales showed high internal consistency reliability (Cronbach's alpha for both scales $=0.84$ ).

Psychological distress was assessed by a list of four conditions (acute anxiety, depression, nervous breakdown, suicidal thoughts), prefaced by the question, "Since ordination have you experienced any of the following?"

Psychosomatic ailments were assessed by a list of five conditions (chronic indigestion, frequent headaches, insomnia, migraines, stomach complaints), prefaced by the question, "Since ordination have you experienced any of the following?"

Thoughts of leaving ministry were assessed by the question, "Have you since ordination considered leaving the priesthood?" rated against four responses (no, once or twice, several times, frequently).

\subsection{Analysis}

These data were analyzed with the SPSS package, using the frequency, factor, reliability, correlation, and regression routines. The three independent measures of burnout (psychological distress, psychosomatic ailments, and thoughts of leaving ministry) were regressed against scores for emotional exhaustion in ministry and satisfaction in ministry, with the interaction term included in the model to test for balanced affect. In light of occasional missing values, the sample sizes vary in the analyses between 649 and 658 .

\section{Results}

The first step in data analysis examines the three independent measures of burnout (thoughts of leaving ministry, count of psychosomatic ailments, count of psychological distress). The frequencies of responses to these three questions are presented in Table 1 . These data demonstrate that $71 \%$ of the clergy have never entertained thoughts of leaving ministry, $64 \%$ have logged no signs of psychological distress, and $49 \%$ have logged no signs of psychosomatic ailments. Thus, according to 
the three measures, between $29 \%$ and $51 \%$ of the clergy register some evidence of poor work-related psychological health. Table 2 examines in greater detail the psychometric properties of the four-item Index of Psychological Distress (IPD). These items generate an alpha coefficient of 0.55 . Table 3 examines the psychometric properties of the five-item Index of Psychosomatic Ailments (IPA). These items generate an alpha coefficient of 0.53 .

Table 1. Three independent measures of burnout.

\begin{tabular}{lr}
\hline & $\%$ \\
\hline Thoughts of leaving ministry since ordination? & 70.6 \\
No & 20.0 \\
Once or twice & 6.8 \\
Several times & 2.6 \\
Frequently & \\
Count of psychosomatic ailments (out of 5) & 49.1 \\
None & 26.7 \\
One & 14.6 \\
Two & 4.9 \\
Three & 4.0 \\
Four & 0.8 \\
Five & \\
Count of psychological distress (out of 4) & 64.1 \\
None & 23.1 \\
One & 8.7 \\
Two & 3.0 \\
Three & 1.1 \\
Four & \\
\hline
\end{tabular}

Table 2. Index of Psychological Distress (IPD): Scale properties $(N=658)$.

\begin{tabular}{lccc}
\hline & $\boldsymbol{r}$ & $f$ & $\%$ \\
\hline Experienced acute anxiety & 0.36 & 0.63 & 19.1 \\
Experienced depression & 0.41 & 0.70 & 26.1 \\
Experienced nervous breakdown & 0.29 & 0.60 & 2.1 \\
Experienced suicidal thoughts & 0.43 & 0.76 & 6.6 \\
alpha/percent of variance & 0.55 & $45.6 \%$ & \\
\hline
\end{tabular}

Notes: $r$ correlation between individual item and sum of other items; $f$ unrotated loading on principal component analysis; \% percent endorsement.

Table 3. Index of Psychosomatic Ailments (IPA): Scale properties $(N=658)$.

\begin{tabular}{lccc}
\hline & $\boldsymbol{r}$ & $f$ & \% \\
\hline Suffer chronic indigestion & 0.33 & 0.61 & 10.5 \\
Suffer frequent headaches & 0.38 & 0.69 & 12.3 \\
Suffer insomnia & 0.27 & 0.54 & 20.7 \\
Suffer migraines & 0.23 & 0.51 & 11.1 \\
Suffer stomach complaints & 0.29 & 0.58 & 15.2 \\
alpha / percent of variance & 0.53 & $35.2 \%$ & \\
\hline
\end{tabular}

Notes: $r$ correlation between individual item and sum of other items; $f$ unrotated loading on principal component analysis; \% percent endorsement.

The second step in data analysis examines the two component scales of the Francis Burnout Inventory. Table 4 presents the scale properties of the Scale of Emotional Exhaustion in Ministry (SEEM) in terms of the correlations between each individual item and the sum of the other ten items, factor loadings on the first factor extracted by principal component analysis (unrotated), and the item endorsement (as the sum of the agree strongly and agree responses). These items generate an 
alpha coefficient of 0.87 . In terms of indicators of emotional exhaustion, some idea of the extent of the problem is provided by the following example statistics. Over two-fifths of the clergy reported that they feel drained by their ministry roles $(44 \%)$, and that they find themselves frustrated in their attempts to accomplish tasks important to them (43\%). Nearly two-fifths of the clergy reported that fatigue and irritation are part of their daily experience (39\%) and that they find themselves spending less and less time with those among whom they minister (37\%).

Table 4. Scale of Emotional Exhaustion in Ministry (SEEM): Scale properties $(N=650)$.

\begin{tabular}{lccc}
\hline & $r$ & $f$ & $\%$ \\
\hline I feel drained by fulfilling my ministry roles & 0.62 & 0.71 & 44 \\
Fatigue and irritation are part of my daily experience & 0.68 & 0.77 & 39 \\
I am invaded by sadness I can't explain & 0.56 & 0.65 & 14 \\
I am feeling negative or cynical about the people with whom I work & 0.63 & 0.71 & 14 \\
I always have enthusiasm for my work * & 0.49 & 0.58 & 21 \\
My humour has a cynical and biting tone & 0.38 & 0.47 & 17 \\
I find myself spending less and less time with those among whom I minister & 0.53 & 0.62 & 37 \\
I have been discouraged by the lack of personal support for me here & 0.58 & 0.67 & 20 \\
I find myself frustrated in my attempts to accomplish tasks important to me & 0.59 & 0.68 & 43 \\
I am less patient with those among whom I minister than I used to be & 0.59 & 0.68 & 26 \\
I am becoming less flexible in my dealings with those among whom I minister & 0.62 & 0.70 & 19 \\
alpha/percent of variance & 0.87 & $43.9 \%$ & \\
\hline
\end{tabular}

Notes: $r$ correlation between individual item and sum of other items; $f$ unrotated loading on principal component analysis; \%, percent endorsement. ${ }^{*}$ This item has been reverse coded to compute the correlations, but not the percentage endorsement.

Table 5 presents the scale properties of the Satisfaction in Ministry Scale (SIMS) in terms of the correlations between each individual item and the sum of the other ten items, factor loadings on the first factor extracted by principal component analysis (unrotated), and the item endorsement (as the sum of the agree strongly and agree responses). These items generate an alpha coefficient of 0.88 . In terms of indicators of satisfaction in ministry, the following example statistics provide some indication of the extent to which the negative affect of emotional exhaustion is being off-set by positive affect. Over two-thirds of the clergy report that they are really glad that they entered ministry $(80 \%)$, that they gain a lot of personal satisfaction from working with people in their current ministry $(79 \%)$, that they feel that their pastoral ministry has a positive influence on people's lives $(79 \%)$, that they gain a lot of personal satisfaction from fulfilling their functions in ministry $(76 \%)$, and that they feel their ministry is really appreciated by people $(72 \%)$.

Table 5. Satisfaction in Ministry Scale (SIMS): Scale properties $(N=650)$.

\begin{tabular}{|c|c|c|c|}
\hline & $r$ & $f$ & $\%$ \\
\hline I have accomplished many worthwhile things in my current ministry & 0.57 & 0.66 & 62 \\
\hline I gain a lot of personal satisfaction from working with people in my current ministry & 0.70 & 0.78 & 79 \\
\hline I deal very effectively with the problems of the people in my current ministry & 0.32 & 0.39 & 36 \\
\hline I can easily understand how the people here feel about things & 0.36 & 0.43 & 56 \\
\hline I feel very positive about my ministry here & 0.68 & 0.77 & 59 \\
\hline I feel that my pastoral ministry has a positive influence on people's lives & 0.57 & 0.65 & 79 \\
\hline I feel that my teaching ministry has a positive influence on people's faith & 0.45 & 0.53 & 64 \\
\hline I feel that my ministry is really appreciated by people & 0.64 & 0.73 & 72 \\
\hline I am really glad that I entered ministry & 0.62 & 0.72 & 80 \\
\hline The ministry here gives real purpose and meaning to my life & 0.67 & 0.76 & 64 \\
\hline I gain a lot of personal satisfaction from fulfilling my functions here & 0.76 & 0.83 & 76 \\
\hline alpha/percent of variance & 0.88 & $45.3 \%$ & \\
\hline
\end{tabular}

Notes: $r$ correlation between individual item and sum of other items; $f$ unrotated loading on principal component analysis; \% percent endorsement. 
The third step in data analysis examines the mean scores recorded by clergymen and by clergywomen on the single item measure of leaving ministry and on the four multi-item measures: the Scale of Emotional Exhaustion in Ministry (SEEM), the Satisfaction in Ministry Scale (SIMS), the Index of Psychosomatic Ailments (IPA), and the Index of Psychological Distress (IPD). The data presented in Table 6 demonstrate that clergymen record significantly higher scores than clergywomen in terms of emotional exhaustion, psychological distress, and thoughts of leaving ministry, while clergywomen record higher scores than clergymen in terms of satisfaction in ministry. There are no sex differences in terms of psychosomatic ailments.

Table 6. Mean scores for clergymen and clergywomen.

\begin{tabular}{|c|c|c|c|c|c|c|}
\hline \multirow{2}{*}{ Scale } & \multicolumn{2}{|c|}{ Men (494) } & \multicolumn{2}{|c|}{ Women (164) } & \multirow[t]{2}{*}{$t$} & \multirow[t]{2}{*}{$p<$} \\
\hline & $M$ & $S D$ & $M$ & $S D$ & & \\
\hline Emotional exhaustion & 29.33 & 7.58 & 28.01 & 6.99 & 1.9 & 0.05 \\
\hline Satisfaction in ministry & 40.52 & 6.13 & 41.58 & 5.06 & 2.0 & 0.05 \\
\hline Psychosomatic ailments & 0.68 & 1.02 & 0.76 & 1.00 & 0.9 & NS \\
\hline Psychological distress & 0.59 & 0.87 & 0.37 & 0.79 & 2.5 & 0.05 \\
\hline Thoughts of leaving & 1.46 & 0.75 & 1.27 & 0.65 & 2.9 & 0.01 \\
\hline
\end{tabular}

The fourth step in data analysis examines the bivariate correlation between the key variables. Given the significant sex differences, Table 7 presents these associations in terms of partial correlations controlling for sex differences. These data demonstrate a significant negative correlation between emotional exhaustion in ministry and satisfaction in ministry of a size that shows these two variables to be closely associated but not merely mirror images of one other. These data also demonstrate that the three independent measures of burnout (thoughts of leaving ministry, psychosomatic ailments, and psychological distress) are all significantly positively correlated with emotional exhaustion, and all significantly negatively correlated with satisfaction in ministry.

Table 7. Correlation matrix controlling for sex differences $(N=640)$.

\begin{tabular}{lclll}
\hline & SEEM & SIMS & Phys & Psyc \\
\hline Thoughts of leaving & $0.38^{* * *}$ & $-0.32^{* * *}$ & $0.28^{* * *}$ & $0.42^{* * *}$ \\
Psychological distress & $0.32^{* * *}$ & $-0.15^{* * *}$ & $0.44^{* * *}$ & \\
Psychosomatic ailments & $0.34^{* * *}$ & $-0.13^{* * *}$ & & \\
SIMS & $-0.68^{* * *}$ & & \\
\hline \multicolumn{5}{c}{ Notes: $^{*} p<0.05 ;{ }^{* *} p<0.01^{* * *} p<0.001}$.
\end{tabular}

The fifth and final step in data analysis examines the notion of balanced affect. To test this notion, the effects of SEEM and SIMS scores on the three independent measures of burnout were tested in a multiple regression model in which SEEM and SIMS scores were allowed to interact. The data presented in Table 8 demonstrate that the interaction term is statistically significant in terms of thoughts of leaving ministry and in terms of psychological distress, but not in terms of psychosomatic ailments. In each case, the interaction term suggests that the mitigating effects of satisfaction in ministry on burnout were greater when the level of emotional exhaustion was higher. 
Table 8. Multiple regression of burnout indicators against the SEEM and SIMS scales.

\begin{tabular}{|c|c|c|c|c|c|c|}
\hline & \multicolumn{2}{|c|}{ Thoughts of Leaving } & \multicolumn{2}{|c|}{ Psychosomatic Ailments } & \multicolumn{2}{|c|}{ Psychological Distress } \\
\hline & B & SE & B & $\mathrm{SE}$ & B & SE \\
\hline Constant & 0.582 & 0.760 & $-3.39 * *$ & 1.09 & $-3.47^{* * *}$ & 0.920 \\
\hline Sex & $-0.132 *$ & 0.061 & 0.140 & 0.087 & -0.138 & 0.073 \\
\hline Age & $-0.098^{* *}$ & 0.031 & -0.068 & 0.044 & -0.049 & 0.038 \\
\hline SEEM & $0.064^{* *}$ & 0.020 & $0.096^{* * *}$ & 0.028 & $0.114 * * *$ & 0.024 \\
\hline SIMS & 0.014 & 0.016 & $0.058 *$ & 0.023 & $0.073^{* * *}$ & 0.020 \\
\hline SEEM * SIMS & $-0.0009 *$ & 0.0005 & -0.0009 & 0.0007 & $-0.0165^{* *}$ & 0.0006 \\
\hline$R^{2}$ (adjusted) & 0.17 & & 0.13 & & 0.12 & \\
\hline
\end{tabular}

\section{Conclusions}

The primary aim of the present study was to test the coherence of the balanced-affect model of professional burnout proposed by the Francis Burnout Inventory among a sample of Anglican clergy serving in the Church of England. This aim was met by identifying three independent indicators of burnout and by examining the effects of the interaction term of the two measures of positive affect and negative affect proposed by the Francis Burnout Inventory in predicting individual differences in scores recorded on these three independent measures. Using thoughts of leaving ministry and psychological distress as independent measures of burnout the data confirmed the statistical significance of that interaction term. As clergy became more emotionally exhausted, their thoughts of leaving ministry and their awareness of psychological stress increased, but these factors are somewhat mitigated when clergy maintain a higher sense of satisfaction in their ministry. However, the interaction term did not reach statistical significance with respect to psychosomatic ailments. This latter measure may be a less effective proxy of burnout than that provided by thoughts of leaving ministry or by psychological distress.

The present study also identified two secondary research aims. The first of these secondary research aims led to the development of two new measures accessing aspects of the work-related psychological wellbeing of clergy: a four-item measure of psychological distress and a five-item measure of psychosomatic ailments. The data suggest that there may be interest and value in exploring these new measures in further research. The second of these secondary research aims gave attention to information generated by the measures of positive affect and of negative affect proposed by the Francis Burnout Inventory. These data suggest that Anglican clergy may be experiencing unhelpful levels of emotional exhaustion in ministry, alongside quite high levels of satisfaction in ministry.

A clear weakness with the present study concerns the problematic nature of specifying adequate measures of burnout against which the balanced affect model may be tested. The study reported by Francis et al. (2011) employed two single-item measures of self-perceived physical health and self-perceived burnout. The present study employed a single-item measure of thoughts of leaving ministry and two multi-item measures of psychological distress and psychosomatic ailments. These measures are also of limited value. Future research in this tradition may need to identify more conceptually sophisticated and more empirically robust measures.

In spite of the problematic notion of the criterion variables, the findings reported by the present study, together with the findings reported by Francis et al. (2011), suggest that the balanced affect model of professional burnout among clergy is not only conceptually coherent, but also empirically verifiable. The practical implications of this finding for supporting the work-related psychological health of clergy are important. While those mandated with the professional and personal oversight of clergy may have a proper duty of care to lower the levels of emotional exhaustion experienced in ministry, they may also have an equal duty of care to enhance the levels of satisfaction in ministry, and this latter task may prove to be both more achievable and more effective. 
Author Contributions: Leslie Francis took the lead in conceptualization, Christine Brewster in data organization, Patrick Laycock in data analyses.

Conflicts of Interest: The authors declare no conflict of interest.

\section{References}

Adams, Christopher J., Holly Hough, Rae Jean Proeschold-Bell, Jia Yao, and Melanie Kolkin. 2017. Clergy burnout: A comparison study with other helping professions. Pastoral Psychology 66: 142-75. [CrossRef]

Barnard, Laura K., and John F. Curry. 2012. The relationship of clergy burnout to self-compassion and other personality dimensions. Pastoral Psychology 61: 149-63. [CrossRef]

Bradburn, Norman M. 1969. The Structure of Psychological Well-Being. Chicago: Aldine.

Brewster, Christine E., Leslie J. Francis, and Mandy Robbins. 2011. Maintaining a public ministry in rural England: Work-related psychological health and psychological type among Anglican clergy serving in multi-church benefices. In The Public Significance of Religion. Edited by Hans-Georg Ziebertz and Leslie J. Francis. Leiden: Brill, pp. 241-65.

Buys, Chenelle, and Sebastian Rothmann. 2010. Burnout and engagement of Reformed Church Ministers. SA Journal of Industrial Psychology 36: 1-11. [CrossRef]

Chandler, Diane J. 2009. Pastoral burnout and the impact of personal spiritual renewal, rest-taking, and support system practices. Pastoral Psychology 58: 273-87. [CrossRef]

Crea, Giuseppe, and Leslie J. Francis. 2015. Professional burnout among Catholic religious sisters in Italy: An empirical enquiry exploring the protective role of quality of community life. Research in the Social Scientific Study of Religion 26: 266-90. [CrossRef]

Doolittle, Benjamin R. 2007. Burnout and coping among parish-based clergy. Mental Health. Religion and Culture 10: 31-38. [CrossRef]

Doolittle, Benjamin R. 2010. The impact of behaviours upon burnout among parish-based clergy. Journal of Religion and Health 49: 88-95. [CrossRef] [PubMed]

Durkee-Lloyd, Janet. 2016. The relationship between work-related psychological health and psychological type among Canadian Baptist clergy: A research report. Journal of Empirical Theology 29: 201-11. [CrossRef]

Evers, Welko, and Will Tomic. 2003. Burnout among Dutch Reformed pastors. Journal of Psychology and Theology 31: 329-38.

Francis, Leslie J., and Giuseppe Crea. 2015. Work-related psychological health and psychological type: A study among Catholic priests in Italy. Mental Health, Religion and Culture 18: 593-604. [CrossRef]

Francis, Leslie J., Sean Gubb, and Mandy Robbins. 2012. Work-related psychological health and psychological type among Lead Elders within the New Frontiers network of churches in the United Kingdom. Journal of Prevention and Intervention in the Community 40: 233-45. [CrossRef] [PubMed]

Francis, Leslie J., Peter Kaldor, Mandy Robbins, and Keith Castle. 2005. Happy but exhausted? Work-related psychological health among clergy. Pastoral Sciences 24: 101-20.

Francis, Leslie J., Patrick Laycock, and Christine Brewster. 2015. The burdens of rural ministry: Identifying and exploring the correlates of five causes of stress among rural Anglican clergy serving in multi-parish benefices. Research in the Social Scientific Study of Religion 26: 218-36. [CrossRef]

Francis, Leslie J., Stephen H. Louden, and Christopher J. F. Rutledge. 2004. Burnout among Roman Catholic parochial clergy in England and Wales: Myth or reality? Review of Religious Research 46: 5-19. [CrossRef]

Francis, Leslie J., Victor John Payne, and Mandy Robbins. 2013. Psychological type and susceptibility to burnout: A study among Anglican clergymen in Wales. In Psychology of Burnout: New Research. Edited by Benjamin R. Doolittle. New York: Nova Science, pp. 179-92.

Francis, Leslie J., Mandy Robbins, Peter Kaldor, and Keith Castle. 2009. Psychological type and work-related psychological health among clergy in Australia, England and New Zealand. Journal of Psychology and Christianity 28: 200-12.

Francis, Leslie J., Mandy Robbins, and Keith Wulff. 2013a. Assessing the effectiveness of support strategies in reducing professional burnout among clergy serving in The Presbyterian Church (USA). Practical Theology 6: 319-31. [CrossRef] 
Francis, Leslie J., Mandy Robbins, and Keith Wulff. 2013b. Are clergy serving yoked congregations under greater stress? A study among clergy serving in The Presbyterian Church (USA). Stress and Health 29: 113-16. [CrossRef] [PubMed]

Francis, Leslie J., and Christopher J. F. Rutledge. 2000. Are rural clergy in the Church of England under greater stress? A study in empirical theology. Research in the Social Scientific Study of Religion 11: 173-91.

Francis, Leslie J., and Douglas W. Turton. 2004a. Reflective ministry and empirical theology: Antidote to clergy stress? In Hermeneutics and Empirical Research in Practical Theology: The Contribution of Empirical Theology by Johannes A van der Ven. Edited by Chris A. M. Hermans and Mary E. Moore. Leiden: Brill, pp. 245-65.

Francis, Leslie J., and Douglas W. Turton. 2004b. Recognising and understanding burnout among the clergy: A perspective from empirical theology. In Building Bridges over Troubled Waters: Enhancing Pastoral Care and Guidance. Edited by David Herl and Mark L. Berman. Lima: Wyndham Hall Press, pp. 307-31.

Francis, Leslie J., Douglas W. Turton, and Stephen H. Louden. 2007. Dogs, cats and Catholic parochial clergy in England and Wales: Exploring the relationship between companion animals and work-related psychological health. Mental Health, Religion and Culture 10: 47-60. [CrossRef]

Francis, Leslie J., Andrew Village, Mandy Robbins, and Keith Wulff. 2011. Work-related psychological health among clergy serving in The Presbyterian Church (USA): Testing the idea of balanced affect. Review of Religious Research 53: 9-22. [CrossRef]

Francis, Leslie J., Keith Wulff, and Mandy Robbins. 2008. The relationship between work-related psychological health and psychological type among clergy serving in The Presbyterian Church (USA). Journal of Empirical Theology 21: 166-82. [CrossRef]

Golden, Jonothan, Ralph L. Piedmont, Joseph W. Ciarrocchi, and Thomas Rodgerson. 2004. Spirituality and burnout: An incremental validity study. Journal of Psychology and Theology 32: 115-25.

Herrera, Helena L., Ignacio Pedrosa, MP Vincente Galindo, Javier Suárex-Álvarez, MP Galindo Villardón, and Eduardo García-Cueto. 2014. Multivariate analysis of burnout syndrome in Latin American priests. Psicothema 26: 227-34. [CrossRef]

Hills, Peter, Leslie J. Francis, and Christopher J. F. Rutledge. 2004. The factor structure of a measure of burnout specific to clergy, and its trial application with respect to some individual difference. Review of Religious Research 46: 27-42. [CrossRef]

Joseph, Eugene N., Jozef Corveleyn, Patrick Luyten, and Hans De Witte. 2010. Does commitment to celibacy lead to burnout or enhanced engagement? European Journal of Mental Health 5: 187-204. [CrossRef]

Joseph, Eugene N., Patrick Luyten, Jozef Corveleyn, and Hans De Witte. 2011. The relationship between personality, burnout, and engagement among the Indian clergy. International Journal for the Psychology of Religion 21: 276-88. [CrossRef]

Küçüksüleymanoğlu, Rüyam. 2013. Occupational burnout levels of Turkish imams. Review of Religious Research 55: 27-42. [CrossRef]

Maslach, Christine, and Susan E. Jackson. 1986. Maslach Burnout Inventory: Manual. Palo Alto: Consulting Psychologists Press.

Miner, Maureen H. 2007a. Changes in burnout over the first 12 months in ministry: Links with stress and orientation to ministry. Mental Health, Religion and Culture 10: 9-16. [CrossRef]

Miner, Maureen H. 2007b. Burnout in the first year of ministry: Personality and belief style as important predictors. Mental Health, Religion and Culture 10: 17-29. [CrossRef]

Parker, Philip D., and Andrew J. Martin. 2011. Clergy motivation and occupational well-being: Exploring a quadripolar model and its role in predicting burnout and engagement. Journal of Religion and Health 50: 656-74. [CrossRef] [PubMed]

Raj, Anthony, and Karol E. Dean. 2005. Burnout and depression among Catholic priests in India. Pastoral Psychology 54: 157-71. [CrossRef]

Randall, Kelvin. 2004. Burnout as a predictor of leaving Anglican parish ministry. Review of Religious Research 46: 20-26. [CrossRef]

Randall, Kelvin. 2007. Examining the relationship between burnout and age among Anglican clergy in England and Wales. Mental Health, Religion and Culture 10: 39-46. [CrossRef]

Randall, Kelvin. 2013a. Clergy burnout: Two different measures. Pastoral Psychology 62: 333-41. [CrossRef] 
Randall, Kelvin. 2013b. Examining thoughts about leaving the ministry among Anglican clergy in England and Wales: Demographic, churchmanship, personality and work-related psychological health factors. Practical Theology 6: 178-89. [CrossRef]

Robbins, Mandy, and Leslie J. Francis. 2010. Work-related psychological health among Church of England clergywomen: Individual differences and psychological type. Review of Religious Research 52: 57-71.

Robbins, Leslie, and Leslie J. Francis. 2014. Taking responsibility for multiple churches: A study in burnout among Anglican clergywomen in England. Journal of Empirical Theology 27: 261-80. [CrossRef]

Robbins, Mandy, Leslie J. Francis, and Ruth Powell. 2012. Work-related psychological health among clergywomen in Australia. Mental Health, Religion and Culture 15: 933-44. [CrossRef]

Rodgerson, Thomas E., and Ralph L. Piedmont. 1998. Assessing the incremental validity of the Religious Problem-Solving Scale in the prediction of clergy burnout. Journal for the Scientific Study of Religion 37: 517-27. [CrossRef]

Rossetti, Stephen J. 2011. Why Priests Are Happy: A Study of the Psychological and Spiritual Health of Priests. Notre Dame: Ave Maria Press.

Rutledge, Christopher J. F. 2006. Burnout and the practice of ministry among rural clergy: Looking for the hidden signs. Rural Theology 4: 57-65. [CrossRef]

Rutledge, Christopher J. F., and Leslie J. Francis. 2004. Burnout among male Anglican parochial clergy in England: Testing a modified form of the Maslach Burnout Inventory. Research in the Social Scientific Study of Religion 15: 71-93.

Stanton-Rich, Howard M., and Seppo E. Iso-Ahola. 1998. Burnout and leisure. Journal of Applied Social Psychology 28: 1931-50. [CrossRef]

Sterland, Sam. 2015. Workaholism and burnout in Australian church workers. Research in the Social Scientific Study of Religion 26: 250-65. [CrossRef]

Strümpfer, D.J. W., and J. Bands. 1996. Stress among clergy: An exploratory study on South African Anglican priests. South African Journal of Psychology 26: 67-75. [CrossRef]

Turton, Douglas W., and Leslie J. Francis. 2007. The relationship between attitude toward prayer and professional burnout among Anglican parochial clergy in England: Are praying clergy healthier clergy? Mental Health, Religion and Culture 10: 61-74. [CrossRef]

Virginia, Stephen G. 1998. Burnout and depression among Roman Catholic secular, religious, and monastic clergy. Pastoral Psychology 47: 49-67. [CrossRef]

Warner, Janelle, and John D. Carter. 1984. Loneliness, marital adjustment and burnout in pastoral and lay persons. Journal of Psychology and Theology 12: 125-31. 